\title{
Análise automática de manifestações emocionais em PB: aplicações do programa ExProsodia
}

\author{
Waldemar Ferreira Netto
}

\section{Introdução}

A análise da manifestação das emoções associadas à fala tem sido objeto de especulação científica desde o século XIX. Darwin (2000) já afirmara que a tonalidade da voz tem relação com certos sentimentos, exemplificando que uma pessoa delicadamente reclamando de maus-tratos, ou de um pequeno sofrimento, quase sempre fala com voz aguda. Spencer (1890) afirmara que era inegável que certos tons de voz e cadências que têm alguma semelhança com a natureza sejam espontaneamente usados para expressar tristeza, para expressar alegria, para expressar o afeto e para expressar o triunfo ou ardor marcial. Embora tais proposições se estendessem para além da preocupação com manifestação das emoções, o reconhecimento da entoação como um fato comunicativo, voluntário ou não, teve seu início no século XIX, mas não recebeu uma atenção aprofundada nos estudos referentes à comunicação humana.

Numa das primeiras pesquisas que procurou descrever de forma mais sistemática a relação entre a variação de frequência e a manifestação das emoções na fala, Skinner (1935) verificou que a frequência média na fala, provocada pela alegria (happiness) era mais aguda do que a provocada pela tristeza (sadness). Sua pesquisa baseou-se na hipótese de que um estado emocional geral seria induzido pela audição prévia de 
músicas tristes ou alegres e, ainda, acompanhada da audição de textos igualmente tristes ou alegres. Esse estado emocional provocaria naturalmente as manifestações sonoras correspondentes na fala. Para tanto, ele gravou e analisou a expressão curta "ah" de cada um de seus sujeitos. A interpretação da curva de F0 dessa expressão foi feita a partir do harmônico mais grave do espectra calculado.

Alguns anos depois, Fairbanks e Pronovost (1938; 1939) procurariam estabelecer a relação entre as variações da entoação e a manifestação das emoções na fala, bem como o julgamento dessas emoções por sujeitos ouvintes. A partir da fala simulada com leituras feitas por atores, os autores analisaram comparativamente as variações de F0 para as manifestações emocionais de desprezo (contempt), raiva (anger), medo (fear), tristeza (grief) e indiferença (indifference). Para essa comparação, estabeleceram quatro parâmetros: o valor médio da frequência em que ocorrem as manifestações emocionais (pitch level) medida em Hz; a variação tonal média, medida em tons musicais (wide mean inflectional range); a extensão tonal em que ocorrem essas manifestações, medida em tons musicais (wide total pitch range); e, a taxa de variação tonal em que ocorrem essas manifestações emocionais (pitch change) (medida em tons por segundo). As comparações foram feitas baseadas nos valores máximos e mínimos encontrados para esses parâmetros. Os resultados obtidos mostraram que manifestações de raiva e de medo ocorrem com a frequência média mais aguda e que indiferença ocorre com a mais grave. No entanto, no teste de avaliação dessas emoções, foram consideradas como desprezo, tristeza e indiferença todas as leituras cuja frequência média fosse a mais grave. Quanto à extensão tonal, as manifestações de desprezo e de raiva foram as que apresentaram valores mais altos e a manifestação de indiferença apresentou a mais baixa. A manifestação de tristeza teve a menor variação tonal e a manifestação de raiva, a maior. 
Quanto à taxa de variação tonal, a mais rápida foi a manifestação de raiva e a mais lenta foi a de medo. Fairbanks e seus colegas (1941) analisaram a taxa de duração das mesmas emoções e verificaram que as manifestações de tristeza e de indiferença apresentaram as menores taxas de duração, atribuindo esse fato aos prolongamentos das fonações e às pausas. A partir dos anos 60, essa preocupação foi retomada com diversos autores (MARKEL, 1965; COSTANZO et al., 1969, WILLIAMS et al., 1972. Para uma revisão de trabalhos desse período, cf. SCHERER, 1986).

Em investigação semelhante à de Skinner (1935), Bachrorowski e Owren (1995) analisaram um segmento vocálico de fala de sujeitos que eram submetidos a situações provocadoras de emoções positivas e de emoções negativas. Tomando medidas de F0, jitter e shimmer, os autores chegaram a resultados semelhantes: as situações em que emoções positivas eram estimuladas estabeleceram F0 mais agudo do que às que provocaram emoções negativas. Como os autores não trataram de nenhuma emoção específica, como nos trabalhos anteriores, é possível estabelecer que as manifestações de emoções negativas, que decorriam de um teste no qual o sujeito não conseguia alcançar os resultados previstos, eram mais propriamente relacionadas à frustração ou tristeza. A partir do ano 2000 , o número de investigações que procuram descrever a relação entre a manifestações das emoções e as características acústicas da fala cresce vertiginosamente. [ANG et al, s.d.; FUJISAWA et al., 2003; TOIVANEN et al., 2004; VOGT et al., 2005; COOK et al, 2006; VIDRASCU; DEVILLERS, 2007; RONG et al, 2007; NEIBERG; ELENIUS, 2008; BUSSO et al., 2009; YANG; LUGGER, 2010; LAUKKA et al., 2011).

Em trabalho mais recente, Bänzinger e Scherer (2005), num estudo quantitativo, verificaram que a variação global de F0 era afetada diretamente pelo estímulo emocional representado na 
fala e era a variação mais importante para a discriminação das categorias emocionais observadas. A partir de 1998, com o trabalho de Slaney e McRoberts (1998), dados espontâneos de fala dirigida às crianças começaram a ser utilizados em estudos de análise automática da fala. Recentemente, um grande número de pesquisas tem utilizado a fala espontânea (cf. BARTLINER et al., 2011 para um levantamento mais detalhado).

Os estudos que tratam de fala emotiva em português brasileiro aparecem com maior frequência a partir da década de 1990. Colamarco e Moraes (2008) analisaram 16 repetições de uma sentença padrão combinando emoções e tipos de sentença. $O$ resultado apontou para uma independência entre a entoação com função gramatical e a entoação expressiva ligada à manifestação das emoções.

O estudo de Vassoler e Martins (2013) analisou trechos de fala atuada lidos por três atrizes profissionais, subdivididos em raiva e neutro. Como resultado das análises, os trechos de fala com raiva obtiveram maiores valores de F0, ou seja, foram produzidos num registro mais alto que os trechos de fala neutra. Os autores forneceram duas explicações, uma de ordem fisiológica e outra linguística. Na primeira, os músculos e as cartilagens ligados à produção da fala recebem maior tensão, provocando o aumento da pressão subglotal e, consequentemente, causando a elevação dos valores de F0 (TITZE et al., 1995). Do ponto de vista linguístico, os padrões entoacionais entre os dois tipos de fala analisados permaneceu estável, sendo a implementação fonética - sujeita a condições de produção internas e internas ao sujeito - a principal fonte de diferença entre a fala neutra e a com raiva.

Peres $(2014 ; 2015)$ analisou a emoção na fala por meio de análise de produção e percepção. A análise de produção foi baseada em parâmetros acústicos entoacionais e de qualidade vocal. Para a análise, 32 excertos de fala espontânea do 
português brasileiro foram selecionados e divididos igualmente entre raiva, medo, alegria e tristeza. O teste de percepção foi feito por ingleses e brasileiros. Como esperado, o grau de concordância entre os brasileiros foi mais alto do que entre os ingleses. Os participantes, ingleses e brasileiros, quando equivocados no julgamento, tenderam a associar raiva com alegria, e tristeza com medo. O alto número de respostas corretas dadas pelos participantes brasileiros pode ser explicado pelo papel do léxico e pelo conhecimento pragmático da língua, já o desempenho dos ingleses pode ser explicado pela falta deles. Para isolar o papel do léxico na percepção, trechos com fala delexicalizada também foram analisados. Nesse caso, ouvintes brasileiros tiveram resultado significativo no teste de percepção, ao passo que os participantes ingleses tiveram uma performance aleatória.

Neste estudo, optou-se pelo uso de fala espontânea por ela ser portadora da expressão autêntica da emoção na fala. A maioria dos estudos que trataram da fala expressiva faziam uso de sentenças com fala teatral ou outros tipos de elicitação, como em Scherer e seus colegas (2013).

A utilização de fala atuada ou elicitada tem a seu favor o controle dos estímulos em sentenças idênticas, pronunciadas nas mais variadas emoções e demais tipos de variação entoacional. Sem dúvida, essa característica permite ao experimentador um maior controle das variáveis que podem influenciar na produção e percepção da fala emotiva. Como argumento a favor do uso de fala atuada, Scherer (1981) atentou para os problemas encontrados em gravações de fala espontânea, sem intervenção direta do experimentador, afirmando que "[...] naturally recorded emotions are by definition singular cases, both in terms of speaker identity, situation context, and verbal content of utterance". Segundo o autor, com essas características da fala espontânea, ficaria difícil 
a separação de quais variáveis estão de fato agindo para configurar a fala expressiva, configurando um problema quanto à ortogonalidade do experimento.

O estudo de Roberts (2011), entretanto, demonstrou que a fala teatral pode ser fortemente impregnada de estereótipos, afirmando que esse tipo de estímulo "may merely reflect stereotypical behaviors that actors are trained to adopt". A utilização desse tipo de fala poderia causar não só diferenças na produção, mas, provavelmente, na percepção dos estímulos.

A despeito da variação que possa haver entre os trechos espontâneos de fala emotiva, este trabalho dá preferência para esse tipo de produção pela possibilidade de obter dados importantes referentes à manifestação da emoção na fala.

\section{O programa de pesquisa ExProsodia}

O programa de pesquisa ExProsodia tem por objetivo propor uma interpretação para a relação entre a entoação e a fala. Teve seu início em 2008. Recebeu, em 2009, apoio do CNPq (processo 400145/2009-0), para a compra de equipamentos de informática (1 computador desktop e um gravador digital $\mathrm{H} 4$ ), de software (Adobe Audition) e de despesas para pesquisa de campo. Em 2010 obteve apoio também do CNPq, pela concessão de uma bolsa de Produtividade em Pesquisa - PQ (processo 300235/2010-0), renovada em 2013 (processo 302664/2013-0). Em 2014, ainda o CNPq aprovou uma bolsasanduíche (processo 99999.007276/2014-01). O programa, desde seu início, teve a conclusão de 5 teses de doutorado, 2 dissertações de mestrado e 10 trabalhos de iniciação científica; tem, em andamento, 3 teses de doutorado e 4 trabalhos de iniciação científica. 


\section{Contribuições e desenvolvimentos futuros}

Em sua primeira concepção, o programa contava com o projeto "ExProsodia - Análise automática da entoação na língua portuguesa" finalizado em 2013. Nesse mesmo ano, o programa foi atualizado com o projeto "Análise automática de manifestações emocionais em PB: aplicações do programa ExProsodia", enfatizando especialmente as manifestações emocionais na produção de fala em língua portuguesa. 0 desenvolvimento desse projeto trouxe algumas contribuições para a aplicação sobretudo nos estudos das disfunções emocionais. As pesquisas adiantaram de forma significativa uma série de parâmetros específicos das manifestações emocionais (FERREIRA NETTO et al., 2014a; FERREIRA NETTO et al., 2014b; FERREIRA NETTO et al., 2014c; SOUSA, 2014; PERES, 2014; 2015; NEGRI, 2015). Dando prosseguimento às pesquisas que haviam iniciado na primeira versão deste projeto, Garcia (2015) realizou pesquisa a respeito da finalização de frases entre falantes não escolarizados na região do médio Tietê, em São Paulo, e na região norte de Portugal, encontrando resultados que corroboram os de Costa (2011) e de Baz (2011) estabelecendo que a hipótese de que é a variável "escolaridade" que interfere desse tipo de construção. Rosa (2015) mostrou que, de fato, falantes alfabetizados têm maior facilidade de percepção das finalizações descendentes. Ainda não se realizaram testes de percepção dessa finalização entre sujeitos não escolarizados.

\section{Colaborações e parcerias}

Desde 2014, o programa tem desenvolvido interações com outras instituições, por meio de atividades conjuntas. Com o Instituto Federal de São Paulo, está em desenvolvimento o projeto "Aplicativo independente para análise das emoções na entoação da fala de língua portuguesa" - coordenado pela Profa. Dra. Maressa de Freitas Vieira (IFSP) e pelo Prof. Dr. Waldemar Ferreira Netto (FFLCH/USP) -; com a Faculdade de 
Medicina Veterinária e Zootecnia da USP e com a Faculdade Sudoeste Paulista está em desenvolvimento o projeto "Aplicativo para análise dos sons animais" - coordenado pela Profa. Dra. Lílian Gregory (FMVZ/USP), pela Profa. Dra. Glenda Maris de Barros Tartaglia (FSO). A participação dos membros da equipe do Programa de Pesquisa ExProsodia em todos esses projetos decorre do estabelecimento de parâmetros para a avaliação automática das manifestações sonoras, seja a produzida pela fala seja a produzida pela voz dos animais. 0 aplicativo ExProsodia ${ }^{\circledR}$, registrado no INPI (RS08992-2), em 2008, com aprovação definitiva em 2010, tem dado os subsídios necessários para as análises até então empreendidas.

\section{Metodologia utilizada}

Para os procedimentos dessa análise automática, toma-se a entoação como uma sucessão de tons iguais ou diferentes que ocorrem na produção da fala. Essa interpretação sugere por si só que a entoação é uma série temporal que sofre a ação de várias componentes para sua configuração momento a momento. Uma série temporal se caracteriza por ser um conjunto de observações sequenciadas e dependentes entre si, isto é, o resultado da observação feita no momento $t+1$ condiciona-se ao resultado da observação feita no momento $t$, à maneira dos processos estocásticos (MORETTIN; TOLOI, 1986; PEREIRA et al., 1986; EHLERS, 2007). A observação das frequências de uma onda sonora estabelece naturalmente uma série temporal na medida em que o valor observado para cada momento depende do valor do momento imediatamente anterior; nenhuma inversão de valores pode ser permitida, mas, ao contrário, a ordem de ocorrência deve ser mantida como uma informação inerente do valor obtido. A trajetória gráfica do conjunto de observações colhidas para o estabelecimento de uma série temporal pode ser interpretada como o resultado da soma de componentes diversas, com características 
independentes. Considerando-se que os valores obtidos mantêm entre si dependência serial, entende-se que se deve buscar o(s) fenômeno(s) que desencadeia(m) essa dependência. Assim, espera-se que os valores obtidos em cada momento resultem de uma conjunção de fatores diversos que, agregados, têm o comportamento observado e mensurado.

Para a decomposição dessa série temporal, assumimos a hipótese proposta por Xu e Wang (1997). Os autores propuseram que a entoação ocorra sob a ação duas componentes principais: as que decorrem de restrições mecânico-fisiológicas e as que decorrem das necessidades expressivas dos falantes. Para o desenvolvimento de nosso trabalho, chamamos às restrições mecânico-fisiológicas de componente estruturadora e às necessidades expressivas, de componente semântico-funcional. A componente estruturadora decorre do esforço fisiológico mínimo dispendido para a produção de sonoridade na laringe. A componente semântico-funcional decorre das necessidades expressivas do falante, tanto para a produção de foco como a produção de ênfase. Em trabalho anterior (FERREIRA NETTO, 2006), propusemos que a componente estruturadora seja formada pelo ritmo tonal. O ritmo tonal é a sucessão dos momentos da fala em que, alternadamente, o falante desencadeia esforço fisiológico para a produção de tom para, em seguida, dispensálo. Desse ponto de vista, ritmo tonal foi decomposto em finalização (F) e sustentação (S). A componente semântico funcional foi definida somente como foco/ênfase (E). 


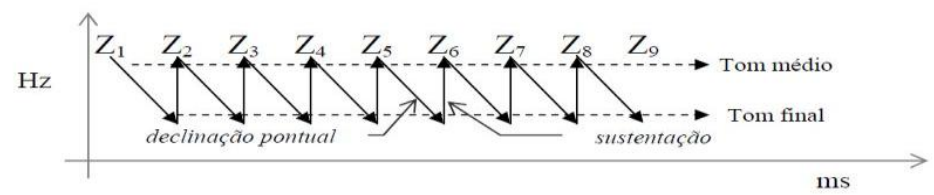

Figura 1. Na figura, o eixo das ordenadas representa as variações em $\mathrm{Hz}$ e o eixo das abscissas, as variações em momentos temporais. A seta pontilhada horizontal superior representa o Tom Médio (TM) tomado de F0 e a seta pontilhada horizontal inferior representa a Finalização (F) de F0. As setas diagonais descendentes representam a tendência à declinação pontual definida momento a momento em direção à $\mathrm{F}$ e as setas verticais representam a tendência à retomada do TM para a sustentação do TM selecionado pelo locutor.

Na medida em que, na fala, a produção de sons tem de ocorrer durante a produção de segmentos soantes e que o falante usa alternadamente segmentos soantes e segmentos obstruintes ou pausas, a entoação é entrecortada sistematicamente, dando origem ao ritmo tonal. Aos momentos em que há produção de som, chamamos de UBI (sigla adaptada da expressão inglesa Unit of Base of Intonation). A ocorrência das UBI, portanto, está restrita às condições mínimas envolvidas na sustentação. Essas condições envolvem as variáveis de frequência, intensidade e duração, que não podem, obviamente, nenhuma delas igualarse a zero; havendo ainda restrições maiores que têm de ser consideradas. Em nossa proposta, entendemos que $20 \mathrm{~ms}, 50$ $\mathrm{Hz}$ e intensidade $>0$ são suficientes para o estabelecimento de uma UBI.

$\mathrm{Na}$ medida em que a produção da fala exige esforço para sustentar a voz com uma frequência relativamente estável, Ferreira Netto $(2006 ; 2008)$ e Peres e seus colegas $(2009,2011)$ 
propuseram a ocorrência de um tom médio ideal (TM) de F0, que se repete nos momentos $Z(t)$ mensurados de F0.

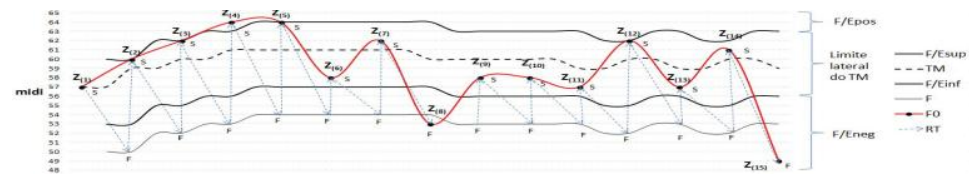

Figura 2. Na figura acima, tem-se a representação do Ritmo Tonal, marcado com linhas azuis pontilhadas, numa ocorrência efetiva de F0, marcado pela linha vermelha contínua. Os valores à esquerda estão em escala midi. As siglas $Z$ indicam cada um dos momentos mensurados de FO (UBIs); as siglas $F$, as finalizações supostas, sendo a que vai marcada no momento $Z_{(8)}$ e a última à direita $\left(Z_{(15)}\right)$ as que realmente se realizaram; as siglas $S$ indicam os pontos de sustentação supostos, que estabelecem o Tom Médio.

A supressão desse esforço desencadeia uma declinação pontual que exige a retomada da tensão inicial. A sustentação (S) é consequência do esforço que se acrescenta a cada um dos momentos da fala, incluindo-se o inicial, para compensar a declinação pontual de finalização (F). Ritmo tonal é consequência da ação dessas tendências que atuam em sentidos opostos, possibilitando a produção da fala. A componente $\mathrm{F}$ associa-se ao fato de que se trata do tom alvo da declinação pontual, estabelecida por um intervalo ideal decrescente de 7 st do TM obtido até o momento $Z(t)$. TM é a tendência central dos valores válidos de FO calculada como a média aritmética acumulada no tempo. A partir dessa frequência média, as frequências são categorizadas por um intervalo sistêmico lateral de 3 st acima e e 4 st abaixo do valor médio de cada uma (MARTINS; FERREIRA NETTO, 2010; 2011). Os valores válidos mensurados são os momentos de F0 (UBIs) que cumprem as restrições de altura, intensidade e duração. A série temporal se configura aditivamente como 
$\mathrm{Z}(\mathrm{t})=\mathrm{S}(\mathrm{t})+\mathrm{F}(\mathrm{t})+\mathrm{E}(\mathrm{t})$. O modelo de análise apresentado permite a análise isolada de cada uma das componentes de FO.

\section{Unidade básica da entoação - UBI}

A seleção das unidades $Z(t)$ - ora chamadas de UBI - para análise é feita pelo aplicativo ExProsodia ${ }^{\circledR}$ (FERREIRA NETTO, 2010). O aplicativo faz a análise automática de porções da curva de frequência estabelecida por autocorrelação pelo software Speech Filing System ${ }^{\circledR}$ (HUCKVALE, 1987, 2008; HUCKVALE et al., 2007). Três parâmetros são considerados para essa definição: frequência maior do que $50 \mathrm{~Hz}$ e menor do que 700 $\mathrm{Hz}$; intensidade maior do que zero e, garantidos os critérios anteriores, duração maior do que 20 ms. Esses valores podem ser modificados pelo usuário.

\section{Frequência}

A seleção de $50 \mathrm{~Hz}$ como frequência mínima deu-se pela manutenção de um intervalo de segurança. $O$ mesmo fato ocorre para as frequências mais agudas, com limite em $700 \mathrm{~Hz}$. Russo e Behlau (1993) verificaram que falantes masculinos do português brasileiro têm uma frequência fundamental em torno de $105 \mathrm{~Hz}$, os do sexo feminino têm $213 \mathrm{~Hz}$, crianças antes da puberdade, em média, $290 \mathrm{~Hz}$ e recém-nascidos, em torno de $440 \mathrm{~Hz}$. Mortari (1990) encontrou para vozes infantis entre sete e nove anos uma variação entre 182 e $281 \mathrm{~Hz}$, para meninos e meninas, sem diferenças marcantes entre eles. Andrade (2003) encontrou para vozes masculinas uma variação média oscilando entre 110 e 146,7 Hz e, para vozes femininas, uma concentração acentuada em torno de 203,5 Hz. Felippe e colegas (2006) propuseram a normatização entre 119 e $120 \mathrm{~Hz}$, para vozes masculinas, e entre 206 e $207 \mathrm{~Hz}$, para vozes femininas. Apesar dessa variação, é possível estabelecer algum limite que abarque essa variação. Russo (1999) propôs que a área da fala, incluindo a frequência fundamental esteja desde $100 \mathrm{~Hz}$ até $8000 \mathrm{~Hz}$, com intensidade variando entre 40 e $65 \mathrm{~dB}$. Tendo em vista 
objetivar-se a análise automática da fala e a população ser bastante heterogênea, optou-se por uma margem de erro mais extensa, sobretudo para as frequências mais graves, de maneira a não se rejeitar ocorrências falso-negativas. O programa de pesquisa ExProsodia considera uma margem de erro de $35 \%$, a partir do valor médio mínimo de $100 \mathrm{~Hz}$ para vozes masculinas (RUSSO 1999), para o qual se pressupõe um valor final de aproximadamente $67 \mathrm{~Hz}$, ou uma quinta descendente (FERREIRA NETTO; CONSONI, 2008), e se estabelece um valor mínimo de $50 \mathrm{~Hz}$. Para valores mais agudos, o limite foi estabelecido arbitrariamente em torno de 2 vezes o valor da frequência média máxima das vozes infantis (ANDRADE, 2003). Esses valores, mínimo, de $50 \mathrm{~Hz}$ e, máximo, de $700 \mathrm{~Hz}$ são, os limites possíveis assumidos para a análise automática aceitar um momento $Z(t)$ como passível de ser UBI.

\section{Intensidade}

Tendo em vista especialmente as variações de frequência da onda sonora, a intensidade é tratada somente como parâmetro de avaliação de audibilidade dessa frequência. O aplicativo SFS analisa a variação de intensidade com uma taxa de amostragem de $200 \mathrm{~Hz}$ e apresenta os resultados como unidades de RMS (root mean square) dos picos de intensidade de porções de 25 ms. Ainda que variações de intensidade da onda sonora sejam reconhecidamente importantes, principalmente para as análises de ritmo, não foram tomadas como referência, por sujeitaremse a estímulos extralinguísticos. Um valor entre 1 e 10 estabelece um corte nos momentos que tenham de $1 / 1$ a 1/10 do valor médio da intensidade, em RMS. Entretanto, conforme já dissemos anteriormente (FERREIRA NETTO et al., 2013b), é possível que a intensidade possa acrescentar informações.

\section{Duração}

Boemio e seus colegas (2005) verificaram que, embora ambos os hemisférios processem informações em duas velocidades 
específicas - 25-50 ms e 200-300 ms - no giro temporal superior, a conexão que se faz com o sulco temporal superior é enfatizada no hemisfério esquerdo na velocidade de $25-50 \mathrm{~ms}$ e no hemisfério direito na velocidade de 200-300 ms. Dessa maneira ambos os hemisférios atuam nas tarefas de percepção linguística, mas cada um terá melhor especialização em tarefas específicas, no caso relativas à duração e à precisão da análise. Os valores apresentados estabelecem a possibilidade de ocorrerem resoluções diferenciadas e simultâneas em cada um dos hemisférios. Quanto aos valores mínimos entre 25-50 ms, outros autores encontraram resultados semelhantes (SCHAEFFER, 1966; HUGGINS, 1972; ROEDERER, 2002; STEVENS, 2000; HENRIQUE, 2002; MENEZES, 2003). Dada a necessidade de segmentar unidades de entoação na fala, a seleção de quatro momentos de análise do SFS, correspondendo a 5 ms cada um, estabelece uma duração mínima de $20 \mathrm{~ms}$. Apesar de os valores mínimos propostos pelos autores já referidos estarem acima dessa opção, é seguro manter uma margem de erro maior para não se incorrer em falso-negativos.

\section{Tom Médio}

Ferreira Netto $(2006 ; 2008)$ propôs que o Tom Médio seja a média aritmética acumulada no tempo de todas as frequências válidas, isto é, que estejam de acordo com os limites de frequência mínima e máxima, duração mínima e máxima e intensidade mínima. Esse valor médio dominante é o que se presume seja a frequência-alvo do ritmo tonal do falante. Martins (2012) definiu o Tom Médio como cada uma das médias da série temporal

$$
\tau=\sum_{i=1}^{n} Z n(t n)
$$


em que $\tau$ é o valor do Tom Médio, $Z$ é cada uma das UBIs encontradas e $t$ é a sua posição na série temporal. $O$ valor do intervalo sistêmico lateral é calculado como $\tau * 1,19$, para o limite superior e $\tau-(\tau * 0,22)$. Esses limites seguem 0 principio estabelecido por T'Hart (1981) e por T'Hart e seus colegas (1990). Esses valores baseiam-se na variação em semitons, 3 st acima do TM e 4 st abaixo, calculando-se uma progressão geométrica de 0,06 para cada semiton. 0 cálculo utilizado para a conversão de $\mathrm{Hz}$ em semitons é

$$
\text { midi }=12 * \log _{2}\left(F_{m} / 440 \mathrm{~Hz}\right)+69
$$

em que midi (WOLF, s. d.) é a adaptação dos valores em $\mathrm{Hz}$ da escala temperada para valores midi, $\mathrm{F}_{\mathrm{m}}$ é a valor em $\mathrm{Hz}$ que se deseja converter para midi (T'HART, 1981; T'HART ET AL., 1990).

\section{Finalização}

A componentes de Finalização $(F)$ foi definida também em Ferreira Netto (2006; 2008). Trata-se de um valor localizado abaixo do Tom Médio, num intervalo de $7 \mathrm{st}$, ou, para valor em $\mathrm{Hz}, \tau-(\tau * 0,35)$ (MARTINS, 2012). O intervalo de 7 st abaixo do Tom Médio equivale a uma variação semelhante a que ocorre num intervalo entre um tom Dominante e um tom Tônica, considerando-se a escala musical temperada. A hipótese de se imaginar a finalização de frases assertivas a partir de um intervalo descendente maior do Tom Médio parte de Ohala (1984) que afirma ocorrer ocasionalmente um pico de FO mais agudo, nas vozes que exibem uma maior confiança, para fazer a queda final parecer ainda mais acentuada, i. e., resultar de uma altura maior. Em Ferreira Netto e Consoni (2008), foi possível verificar que há essa correlação entre Tom Médio e Finalização em frases assertivas da língua portuguesa falada no Brasil, especialmente nas leituras em voz alta. Baz e seus colegas (2014) verificaram que as finalizações assertivas em dados de leitura teatral ocorrem regularmente abaixo de 4 st, ultrapassando o intervalo sistêmico lateral inferior do Tom 
Médio. A pesquisa desenvolvida por Rosa (2015) corrobora esses resultados. Valendo-se de testes de percepção a partir de estímulos de frases espontâneas manipulados digitalmente, a autora verificou que os sujeitos não mostraram regularidade significativa no reconhecimento de frases assertivas com finalização descendente.

Investigando as finalizações frasais assertivas entre mulheres idosas não letradas guatós, Costa $(2009 ; 2010)$ verificou que tais finalizações não ocorrem em tom descendente. Baz (2011) encontrou fenômeno semelhante na fala e na música popular em guarani paraguaio. Com o propósito de verificar se essa característica era influência da fala indígena, Garcia (2015) empreendeu pesquisa entre idosos não letrados na região do médio Tietê e, comparativamente, na região norte de Portugal. Os resultados obtidos corroboraram os de Costa $(2009 ; 2010)$ e de Baz (2011) e demonstraram que somente a variável referente ao letramento era comum a esses indivíduos.

\section{Parâmetros de avaliação}

Como elementos de comparação, além dos parâmetros próprios da extração automática feita pelo ExProsodia, tais como TM, F/E, Duração, Intensidade e Pausa, também serão retomados os parâmetros definidos em trabalhos anteriores (FERREIRA NETTO et al., 2013a; FERREIRA NETTO et al., 2014a). Foram definidos 30 parâmetros, considerando-se $T M, F / E$, duração, intensidade e pausa. 

programa ExProsodia

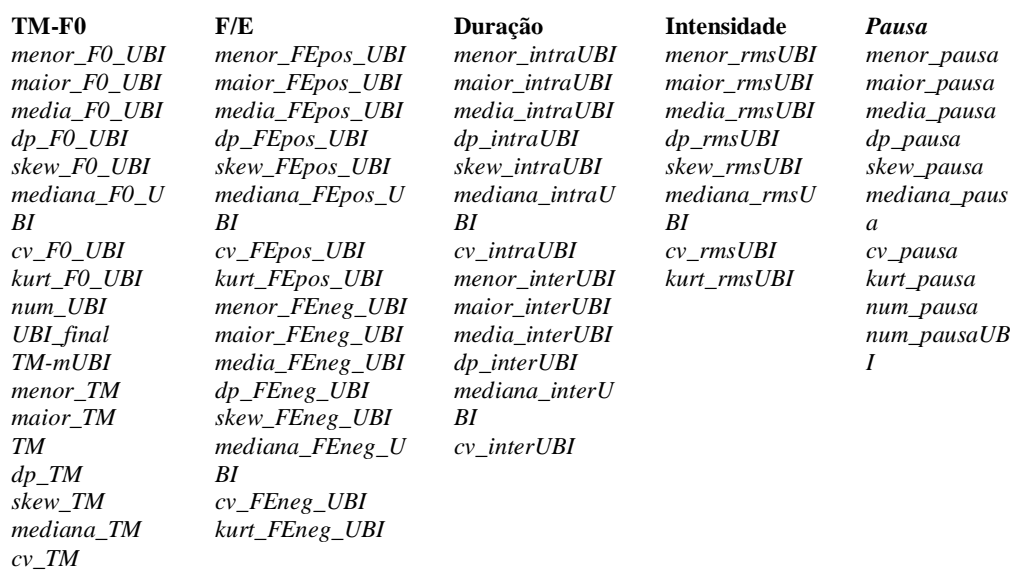

Os parâmetros relativos à frequência partem do TM definido pela análise do ExProsodia ${ }^{\circledR}$ para cada UBI, medido em Hz. Além de TM, TM_dp, TM_cv e de TM_skew, são considerados FOdp_TM (coeficiente de variação de FO); F0_skew (assimetria de F0); mUBI (menor valor válido de UBI); TM_mUBI (diferença entre o TM e o menor valor válido de UBI).

Os parâmetros relativos à componente $F / E$ (foco ênfase) envolvem tanto valores médios acima do TM - F/Epos quanto abaixo - F/Eneg - , tal como foram definidos para cada UBI pelo ExProsodia.

Os parâmetros relativos à duração partem das definições de UBI realizadas pela análise do ExProsodia, medidas em $\mathrm{ms}$. 0 parâmetro entreUBI é o valor médio, em ms, obtido a partir da finalização de uma UBI e o início da seguinte. Para essa definição, foi estabelecido o limite máximo de 500 ms. intraUBI é o valor médio da duração de uma UBI. Nos dois casos serão considerados também o desvio-padrão e o coeficiente de variação.

Os parâmetros relativos à intensidade partem das definições da intensidade média (IM) realizadas pela análise do ExProsodia, 
medida em RMS para cada UBI. O parâmetro IM_cv é o coeficiente de variação médio da intensidade das UBIs. IM_skew é a assimetria média da intensidade verificada nas UBIs.

Os parâmetros relativos às pausas consideram tanto a quantidade de ocorrências de pausas, em relação à quantidade de UBIs - Pausa/UBI - , quanto suas durações intrínsecas, em ms. Neste último caso, são consideradas pausas somente os intervalos entre UBI com duração maior do que $500 \mathrm{~ms}$. Também são considerados o desvio-padrão e o coeficiente de variação.

A seleção dos parâmetros se faz mediante os indicativos apresentados pelos testes estatísticos da análise de clusters (RUSSO et al., 2011) e das comparações múltiplas de Tukey ou Tukey-Kramer, ou ainda do teste de Dunnet. Outras análises poderão ser realizadas, se necessárias.

A aplicação desses parâmetros em conjunto com a análise feita pelo ExProsodia permitem a síntese de curvas entoacionais com o aplicativo PRAAT. Com base nessa síntese, são feitos testes de percepção com o propósito de se certificar de que os parâmetros definidos como significativos são efetivos. 